\title{
BRIDGING PERCEIVED DESTINATION IMAGE AND MARKET SEGMENTATION - AN APPLICATION TO GOLF TOURISM
}

\author{
Antónia Correia ${ }^{\mathrm{*}}$, Nuno Oliveira ${ }^{\mathrm{b}}$ and Filipa Silva ${ }^{\mathrm{c}}$
}

${ }^{a}$ CASEE Centre for Advanced Studies in Economics and Econometrics University of Algarve, Campus de Gambelas, 8000 Faro, Portugal; tel: +351 289800900 ext 7426, e-mail: acorreia@ualg.pt

b London School of Economics - Department of Management, UK, e-mail: n.r.oliveira@lse.ac.uk

${ }^{\mathrm{c}}$ University of Algarve - Faculty of Economics, Portugal

${ }^{*}$ Corresponding author

\begin{abstract}
Motivations, perceptions and expectations are crucial in the build-up process of perceived destination image. This research aims at exploring the multidimensionality of golf destination image, and its heterogeneity among market segments. This research relies on a sample of 100 interviews to golfer tourists visiting six of major golf courses in Vilamoura, Algarve. The findings suggest that motivations, expectations and perceptions are inter-correlated. The findings also highlight three market segments of golf players, namely 'tourist', 'social tourist', and 'player'. Grounded by expectancy value theory framework, we conclude on the heterogeneity of perceived image among segments. Indeed there is a gap between the real destination image and the image perceived by tourists. We argue for the explanatory capital of intrinsic motivations in understanding the idiosyncratic images. Finally this paper enumerates some implications research, management and planning policies.
\end{abstract}

Key words: motivations, perceptions, expectations, destination image, market segments, golf destination

\section{Destination image: An Introduction}

Market analysis has become pivotal in developing tourism destinations in the current atmosphere of competitiveness. As gateway to gain competitive advantage, the destinations have been developed likely brands that have been managed as such. As Kotler, Haider and Rein (1993) suggest, the competitive advantage of tourist regions is contingent upon the capacity to strengthen its features in the global market. Therefore destinations need to be managed from a strategic perspective in which the brand image plays a crucial role for the positioning process (Calantone, Benedetto, Hakam and Bojanic, 1989). According to Beerli (1998), the definition of a strong, coherent, differentiated and identifiable image creates a favourable opinion towards the destination. This opinion is one of the underpinnings for strategic development. 
The importance of the tourism destination image is well-documented in scientific research (Pike, 2002). The destination brand aims at prompting the tourist desire of travelling to a given destination (Gallarza, Saura and García, 2002). The destination brand is grounded in the perceived image about the potential quality of experience at destination. Image is a mental construct formed by a set of attributes perceived and evaluated by tourists. The first stage is activated by the arousal of motivations. Those motivations start the learning process that leads to the stage of uncertain intensity of expectations which influence perceived image, too.

This paper addresses the lack of handful research on the build-up of golf destination image from an expectancy value theory perspective. In line with Selby and Morgan (1996), we endeavour to understand the implications of motivations, expectations and perceptions for the destination image more precisely in golf resort areas. In this study, we propose a multidimensional taxonomy of the interplay of motivations, expectations and perceptions as components of destination image. We put forward the hypothesis on the inter-correlation of the previous three constructs, the existence of various market segments regarding the perceived image, and the heterogeneity of golf destination image among those segments.

The corner stone for scholarly research is the idiosyncratic perceived image held by individuals. The literature has pointed out that destination image differs from the reality (Guthrie and Gale, 1991). Previous research provides modest answers on this question though.

\section{Literature review}

The importance of tourist destination image is universally recognized as it affects the subjective perceptions and the behaviour of the individuals, as well as, the choice of the destination (Gallarza, Saura and García, 2002). The image has been seen as a mental representation formed by a set of attributes that defines the destination. Literature is consensual abouth the strong influence of image on tourist behaviour (Beerli and Martín, 2004). The destination image is even defined by reference to resorts areas which play an important role for the overall image (Prideaux, 2000). Therefore, some questions arise as the perceived image is contingent upon the individuals' motivations and expectations held towards the destination. According to the literature, the expectations may be understood as the consequents (Prebensen and Abelesn, 2003).

\section{Concept of destination image}

Destination image is a multidisciplinary field of research (Ahmed, 1991) which brings together contributes from several disciplines, such as Anthropology (Selwyn, 1996); Sociology (Meethan, 2001) and Marketing (Dann, 1981). As it is patent in numerous studies, destinations with strong and positive image have a greater 
probability of being chosen by tourists (Pearce, 1982; Woodside and Lysonski, 1989; Beerli and Martín, 2004, Silvestre and Correia, 2005) as well as, successfully developing loyalty strategies (Bojanic, 1996, Moutinho, 1982).

The build-up image process is inherently a process of social influence which by its turn is contingent upon the faculty of the destination to provide experiences that meet the feautures of the image that has been previously held about that destination (Chon, 1989; Bigné, Sánchez and Sánchez, 2001; Beerli and Martín, 2004). However, despite the interest in this topic, some authors (MacKay and Fesenmaier, 1997; Baloglu and McCleary, 1999) argue that little research has been conducted on destination image conceptualization and measurement (Beerli and Martín, 2004; Fakeye and Crompton, 1991).

An important development of the image theory applied to tourist destinations has been based on comparison of the image in different phases of the tourist's decision process. Before the purchasing stage, the destination image is essentially a mental construct underpinned by motivations and expectations. Moreover the previous image is related to the psychological factors that provide an individual with the desire of travelling away (i.e. motivations). Expectations refer to instrumentality of the tourism destination (Dann, 1981). After the visit, the destination attributes appears in a much more realistic, objective, differentiated and complex image (Selby and Morgan, 1996). However the perceived image of the destination after the visit is also influenced by motivations, expectations, and perceptions (Worcester, 1997).

Baloglu and McCleary (1999) advocates that the image is formed by a rational and emotional interpretation of the consumer that results from a cognitive evaluation. Following Gunn's concept (1972), several authors acknowledge organic components (information) and induced components (promotion). Even though the image is not a consensual concept since it is composed by several elements, such as experiences, impressions, beliefs, feelings, and knowledge (Moutinho, 1987; Gartner, 1993). Another focus of analysis is the dyadic dimension of image destination which comprises both emotional and cognitive dimensions (Gnoth, 1997; Trauer and Ryan, 2006).

The destination image is either cognitive or emotional (Baloglu and McCleary, 1999). From a cognitive angle, the image on tourist destination is evaluated in terms of a set of attributes that correspond to either the resources or attractions of the destination (Stabler, 1995). Lew (1987) refers that these resources are attracting elements of the destination (e.g. natural environment; activities). The cognitive image is crucial influencing the consumer behaviour and guarantee the success and loyalty of tourist destinations while the emotional image enhances the affective attachment to the destination (Gallarza, Saura, Garcia, 2002). Regarding the lack of consensus around the measurement of destination image (Gartner, 1989), looking at the dyadic view of emotional and cognitive dimensions is thought to be a step ahead in portraying the 
destination image. Literature shows a consensus around the fact that the cognitive component influences emotional component (Holbrook, 1978; Baloglu and McCleary, 1999; Trauer and Ryan, 2006). However we do not know much about the explicative loadings of motivations, perceptions and expectations for the understanding of perceived golf destination image at both emotional and cognitive dimensions. The main shortcoming of the previous research refers to the lack of research attempting to bridge the motivations, expectations and perceived destination image.

\section{Unveiling the tourists' motivations}

The studying of the individual's motivations is one of the most important topics of research in the tourism field. Crompton (1979), Yoon and Uysal (2005) and Dann (1981) classify intrinsic motives as those that predispose the individual for travelling, such as escape from daily routine, the wish to escape from loneliness. Beerli and Martín (2004:626) write that, "motivation is the need that drives an individual to act in a certain way to achieve to the desired satisfaction". By the other hand, destination attributes and believed experiences moderate the destination motivations by its attributes (Buhalis, 2000). Kotler (1982) states that motivations result both from internal and external stimuli. Internal stimuli arise from personal needs that can be physiological, social, egocentric, safety, and self-actualization. External stimuli result from advertising and promoting. Motivations around travelling might be personal (Crompton, 1979) or influenced by the ecosystem (Woodside and Lysonski, 1989).

Early works of Dann (1981) and Crompton (1979) conducted to one of the most well-known model based on the dichotomy of "push" and "pull" motivations. The former refers to socio-psychological motivation that prompts the individual's desire of travel in context of holiday. The later comprises the destination attributes perceived by an individual. Further research (e.g. Lee, Morrison and O’Leary, 2006) report that both push" and "pull" motivations influence the tourist behaviour once in the destination.

Cohen (1972) introduces sociological motives that conduct the tourist to a socially accepted behaviour. Pushing research forward, Gnoth(1997) identifies that the need for holidays depends on the intensity of desires such as self-actualization, selfesteem and social status. Indeed this contributions are akin to the expectancy value theory. In fact, some research has pointed out the legacy of expectancy value theory (Vroom, 1964) to assist the research on motivations and destination choice (Witt and Wright 1992).

Applying the expectancy value theory to the field of tourism, the tourist's motivation is defined by the attractiveness of a valued outcome and the expectancy of achieving that outcome (Ryan and Deci, 2000; Witt and Wright, 1992). For example, the golf player may be attracted by the challenging task of play golf (valence) and his/her expectation to achieve that goal as a personnel accomplishment (expectancy). 
A third concept may be added to the theory - instrumentality which means that a good performance of individual may lead them to a desired outcome, trust, control and selfesteem. Thus, instrumentality is the individual judgement that if an individual meet a performance expectation he will receive a superior compensation (Chiang and Jang, 2008). Again, the golf player may be motivated to this sport because it may be a mean to achieve something, such as social status or recognition. However the linkages between motivation and expectancy value theory remain under-researched.

\section{Expectations}

To the expectancy value theory, instrumentality is akin to the developments advanced by the self-perception theory (Ryan and Deci, 2000). The expectancy of a certain outcome is the cornerstone of the expectancy value theory's concept of Gestalt baked by Tolman (1932). This concept highlights the external stimuli of human behaviour. An assisting tool comes from the concept of self-perception which calls for the importance of the individuals' ability to frame themselves in a certain social context (Bem, 1967; 1972). This self-perception may be defined by reference to an individual level or group level (Tajfel and Turner, 1986). Therefore, the individual expectations might appear aligned to self-perceptions at both the individual and group levels.

In tourism context, expectations result from exposure to external stimuli and vary in terms of the individuals' intrinsic factors (Um and Crompton, 1990). In this way, individuals construct their own mental images which provide the basis for the expected images (Ashworth and Voogd, 1990; Gartner, 1993; Bramwell and Rawding, 1996). The destination attributes are the object of the cognitions which leads to human expectations (Gnoth, 1997). According to the author, expectations are emotionalorientated. This issue has been largely researched in the field of tourist's satisfaction (Oliver, 1997). Indeed this strand of research tends to develop comparatives analyses between expectations and satisfaction aiming at measuring the gap between both concepts.

Expectations play an important role in reducting the psychological tension about the trip (Sherif and Hovland, 1961). The expectations components are contingent upon the promises made by the actors (e.g. tour operators, resorts, and destination advertising) (Bitner, 1990). This posture appears in line with the learning theory according which information sources change the expectations towards the tourism destination (Seabra, Abrantes, and Lages, 2007).

Concerning the golf tourism, research on expectations is an unexploited field of research, particularly when articulated with other concepts such as motivations and perceptions. Recent research has only pointed out the importance of expectations to the golf destination management strategies (Tassiopoulos and Haydam, 2008). 


\section{Perceptions}

Perception is the mechanism by which physical sensations are selected, organised and interpreted. The perceptions develop in the mind of the tourist as a cause and consequence of his/her motivations and expectations (Gnoth, 1997). The perceptions held by tourists are contingent upon the content of the sources of information (e.g. Gartner, 1993; Gunn, 1972). By source of information we understand either advertisement or information circulated by word of mouth. Gunn (1972) points out the role of previous experience in the destination as a crucial proxy to unveil the destination image held by individuals (Chang and Wildt, 1994; Jayanti and Gosh, 1996; Zeithaml, 1998).

According to Howard and Sheth (1969), the previous experience enhances the engagement of the tourist with the destination through a learning process which acts either at the level of perceptions and / or the motivations. According to this strand research, the learning process enhances the individuals to develop expectations and motivations.

\section{Contextual setting}

The tourists visiting the Algarve travel mostly from England and Germany. Ten years ago the number of Irish golf tourists represented 2.9\% of total tourist who have visited the Algarve. In 2005 it was registered the same trend for the three markets (INE, 2006). English market as the more mature and steadiest one. Regarding to golf tourism in Algarve, in the end of the 2006, there were 68 golf courses of 18-hole courses in Portugal from which $46 \%$ were located in Algarve where were sold $1,054,378$ rounds. These figures evidence the importance of Algarve Region for the Portuguese Golf Tourism. Algarve is a well-know golf destination with quality as was awarded in 2006 as "Established Golf Destination of the Year" by IAGTO's specialist golf tour operators. Vilamoura contains six golf courses and 1 of the 50 best golf courses outside of USA (GolfDigest, 2005) that this what is need to have a golf cluster. Therefore, Vilamoura is the main cluster destination in Portugal, not only because the amount of golf courses but also through the amount of infrastructures to support the activity such as: cinemas; five and four stars hotels; Shopping and Leisure areas. These special characteristics represent $6.2 \%$ of the tourist accommodation supply and attract $20 \%$ of the regional demand.

\section{Conceptual Model}

Based on the literature review, the conceptual model aims at bridging the research on motivations, expectations, and perceptions in shaping perceived golf destination image. At a first level, the model aims at testing motivations, expectations and perceptions as both multidimensional and inter-correlated constructs which are 
treated as measures of destination image. Then the model delivers the underpinnings for the analysis of market segmentation and perceived image heterogeneity.

Expectations arise from the pre-purchasing decision phase resulting from a perceptual/cognitive evaluation of the destination. Yet motivations are the starting point of travel decision and will drive the destination choice (Crompton, 1979; Beerli and Martín, 2004; Correia, Barros and Silvestre, 2007).

The Crompton's model (1979) generates the most consensuses in tourism research. The idea behind the model is the division of the tourist motivation into two forces. The first designation is 'push factors', pushing the tourist out of home. In this field, the push motives underlined in the literature rely on personal achievement, satisfaction, adventure, and others connected to social relations such as the desire for recognition, prestige, and to develop new friendships (Crompton, 1979; McCabe, 2000).

The second force is named 'pull factors', directing the individual to a certain destination due to its attributes (Sirakaya, McLellan and Uysal, 1996). Interaction among motivational factors might lead to the heterogeneity of motivations as a whole. Therefore there are linkages among different motivations or even between 'pull' and 'push' factors acting as a dynamic process (Fodness, 1994). Therefore we suggest the following hypothesis:

$\boldsymbol{H}_{1}$ : The golf destination motivations are inter-correlated.

According to Crompton (1979), intangible destination attributes influences the both tourist's expectations and satisfaction. Based on expectancy value theory, expectations might be either at individual or group level (Tolman, 1932). Such findings suggest relationships among the variables that are part of the concept of perceptions. For example, a golf player might weight both levels of expectations towards a final decision of playing in a certain golf course. By inference, it is possible to think of internal relationships among the concept of perceptions through the literature on satisfaction (Olivier, 1997). Reporting the gap between expectations and satisfaction, some authors refer that the failure to meet some expectations has a heavier impact on the overall satisfaction than others (Correia and Pimpão, 2008). Therefore the following hypothesis is deemed necessary to be tested:

\section{$\mathbf{H}_{2}$ : The golf destination expectations are inter-correlated.}

The concept of perception integrates both the cognitive and behavioural perspectives (Sheth, Newman and Gross, 1991; Holbrook and Schindler, 1996). So, perception should be a holistic concept that results from the learning process, combined with the tourist's own motivations. Therefore consumer perception can vary 
from the true product attributes depending on how consumer is able to capture and process information (Zeithaml, 1988). In context of golf destination, Petrick (2001) suggest that overall perception towards the service is a combination of perceptions about single attributes. Therefore, we present the following hypothesis regarding the golf tourism:

$\boldsymbol{H}_{3}$ : The golf destination perceptions are inter-correlated.

The tourist holds his or her own internal and external motivations to travel which lead to different perceptions about the destinations. This assumption is based on Baloglu and McCleary (1999), Dann (1996) and Baloglu (1997). Also, learning theory suggests this path of research. High levels of motivation lead to higher levels of information seeking which provides a wide range of information on destination. Hence, the amount of information tends to shape individual's perceptions on attributes in the destination (Gartner, 1993). So, the following hypothesis comes into light:

\section{$\mathbf{H}_{4}:$ The golf destination perceptions are related with golf tourists' motivations}

The destination image concept is known to be related to tourist expectations as a subjective construction based on cognitive constructions. Expectations interact with destination choice (Gallarza, Saura and García, 2002). Calling the concept of selfperception, it is acknowledgeable linkages between perceptions and expectations. On the ground of rationality individuals tend to set up their expectations according to perceptions (i.e. individuals' expectations might be shaped by reference to perceptions on the destination's attributes). In line with this, we suggest the following hypothesis,

$\boldsymbol{H}_{5}$ : The golf destination perceptions are related with golf tourists' expectations.

Expectancy value theory discloses linkages between motivations and expectations by portraying motivations as a consequence of the expectations (Krippendorf, 1987; Witt and Wright, 1992; Gnoth, 1997). Several authors advocate that expectations follow both cognitive and emotional evaluations (Otto and Ritchie, 1996). Um and Crompton (1990) refer that expectations are moderated by several stimuli and related with information sources and motivations. Woodside and Jacobs (1985) put forward that tourists with high scores on motivations transfer this intensity in expectations. This theoretical posture supports our last hypothesis: 
$\boldsymbol{H}_{6}:$ The golf destination expectations are related with golf tourists motivations.

Figure 1 presents the conceptual model which is bounded by the expectancy value theory. Our hypothesis drawn from the literature will be tested with an exploratory data analysis technique.

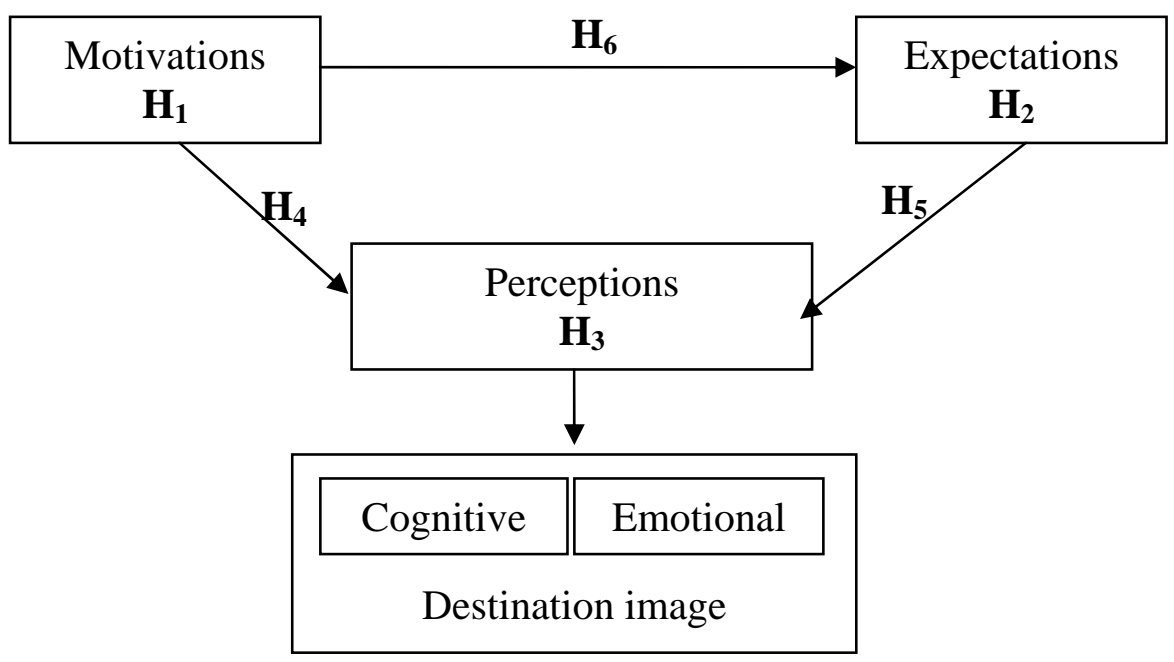

Figure 1 Conceptual model

\section{Methodology}

The survey is representative of the Vilamoura's golf courses. The sampling method used was a random stratified method. A pre-tested interview was delivered to a total of 100 golfers who went to Vilamoura golf courses in 2004. It was considered 80 interviews suitable for analysis which represents a good response rate of $83 \%$. Aiming at reflecting the Vilamoura golf market structure, the stratifying variables are golf course name and country of origin of the golf players.

The majority of the golfers interviewed were from the United Kingdom (65.9\%) followed by Ireland (12.2\%), Scotland (7.3\%), Germany (6.1\%), Portugal (4.9\%). Finally, the group of Belgium, France and USA represents $3.2 \%$ of the total number of players.

A socio-demographic profile is presented in Table 1 . The majority of the golfers are male (78.0\%). The social class was defined based on the composite analysis of three indicators (education level, occupation and disposable income) being the high level class the one that ranks the higher values of the mentioned indicators. All three social classes demonstrated similar values being this a signal that Vilamoura attracts upper and medium social class's tourists. 
Table 1 Sample Characteristics

\begin{tabular}{|c|c|c|}
\hline & Frequency (\%) & Mean \\
\hline Country of Origin & & \\
\hline Portugal & 4.9 & \\
\hline United Kingdom & 65.9 & \\
\hline Ireland & 12.2 & \\
\hline Scotland & 7.3 & \\
\hline Germany & 6.1 & \\
\hline Others & 3.6 & \\
\hline Gender & & \\
\hline Male & 91.5 & \\
\hline Female & 8.5 & \\
\hline Age & & 44.06 \\
\hline Social Class & & \\
\hline High & 37.8 & \\
\hline Medium & 24.3 & \\
\hline Low & 37.8 & \\
\hline
\end{tabular}

Analytical procedures

Gallarza, Saura and Garcia (2002) stressed the application of statistical multivariate techniques to the field of tourism regarding the assessing of the destination image. There are number of examples of multivariate statistics applications in destination image research (Vogt and Andereck, 2003). For example, Silvestre and Correia (2005) explain the image of the Algarve by using a second-order factor analysis; Correia, Valle and Moço (2007) assess motivations and perceptions about exotic destinations by means of a structural model combine with categorical analysis, Selby and Morgan (1996) implemented case study methodology; and, Kim and Yoon (2003) present the formation of perceptions from a conceptual point of view.

The survey was based on a structured questionnaire essentially formed by closed questions assessing expectations, motivations, and perceptions related to golf destination image. This questionnaire was designed based on previous research of Correia, Barros and Silvestre (2007). Starting from a questionnaire previously tested allow to compare results and achieve similar conclusions from other methods. The first research stage employees a Principal Components Analysis (PCA) to operate a data reduction of the variables used to measure expectations, motivations and perceptions. PCA is a technique largely employed for data reduction by extracting information from variable to squeeze it into factors (Greenacre, 1983). Correlations assist us in unveiling the links among each of observed variables for each concept, as well as, among 
constructs

(i.e.

perceptions/expectations;

motivations/perceptions;

motivations/expectations).

The second level of analysis relies on non hierarchical cluster analysis confirmed with discriminant analysis (Crask and Perreault, 1977). In next stage, the analysis includes CATPCA ${ }^{1}$. Heiser and Meulman (1994) to confirm that there are differences within the clusters in what concern their perceptions, expectations and motivations. This technique is usually used to transform an original set of qualitative variables, measured by an ordinal or nominal scale, into a smaller set of new variables (usually referred to as dimensions) without the loss of significant information, (Leeuw and Heiser, 1980; Heiser and Meulman, 1994). All analyses in this study were performed with SPSS 14.

\section{Findings}

Internal taxonomy of motivations, expectations, and perceptions

The first approach to data encompasses two steps, namely data reduction through identifying components in each concept, and computing the correlations among those factors. Principal Components Analysis identifies three main motivation factors which account for $63.59 \%$ of the total variance. The fit tests show good levels, $\operatorname{KMO}(0,865)$ and Bartlett's test of sphericity was significant at $\mathrm{p}=0.000$ for motivation (Hair et al., 1998). After VARIMAX rotation, variables whose eigenvalues were superior to 0.5 were divided into three factors, namely: 'social' (28.48\%), 'leisure' (20.67\%) and 'sports' (14.44\%). All factors show high levels of internal consistency, which is confirmed by Cronbach's Alpha coefficient. All values are higher than 0.8 which provides evidence of the internal consistency.

The driving motivation identified as 'sports' is defined by determinants of a proactive nature such as, 'to play and develop golf skills' (0.840), 'to attend to tournaments' $(0.684)$ and 'to play a competitive sport' $(0.870)$. 'Social'encompasses more social variables, such as “to be adventurous' (0.759), 'to meet people with similar interests' (0.697) and 'to make friends' (0.692). The variable related to knowledge enlargement has the lowest loading (0.612) A third driving motivation, 'leisure', was found to encompass the components, such as 'to avoid the routine (0.750) and 'to alleviate the stress' $(0.702)$. Therefore the leisure factor highlights the need of physical and emotional rest.

${ }^{1}$ Categorical Principal Component Analysis 
Table 2 Principal Components Analysis after VARIMAX rotation for motivations

\begin{tabular}{|l|l|l|c|c|c|}
\hline \multicolumn{1}{|c|}{ Components } & $\begin{array}{c}\text { Eigen } \\
\text { value }\end{array}$ & $\begin{array}{c}\text { Percent } \\
\text { explained } \\
\text { variance }\end{array}$ & $\begin{array}{c}\text { Consistency } \\
\text { (Cronbach's } \\
\text { Alpha) }\end{array}$ & Mean & $\begin{array}{c}\text { Standard } \\
\text { deviation }\end{array}$ \\
\hline Social & & $28.479 \%$ & 0.931 & & \\
\hline To stimulate emotions & 0.770 & & & 4.42 & 1.722 \\
\hline To be adventurous & 0.759 & & & 4.57 & 1.837 \\
\hline $\begin{array}{l}\text { To meet people with similar } \\
\text { interests }\end{array}$ & 0.667 & & & 4.71 & 1.818 \\
\hline To make friends & 0.692 & & & 4.57 & 1.714 \\
\hline $\begin{array}{l}\text { To visit place where my } \\
\text { friends have never been }\end{array}$ & 0.718 & & & 4.18 & 1.802 \\
\hline $\begin{array}{l}\text { To talk about the trip with } \\
\text { my friends }\end{array}$ & 0.665 & & & 4.35 & 1.858 \\
\hline To take some risky & 0.827 & & & 3.54 & 1.896 \\
\hline $\begin{array}{l}\text { To stay and enjoy a natural } \\
\text { area }\end{array}$ & 0.655 & & & 4.78 & 1.841 \\
\hline Leisure & 0.702 & $20.673 \%$ & 0.848 & & \\
\hline To alleviate the stress & 0.750 & & & 5.01 & 1.458 \\
\hline To avoid the routine & 0.760 & & & 5.15 & 1.664 \\
\hline $\begin{array}{l}\text { To relax the mind and the } \\
\text { body }\end{array}$ & 0.612 & & & 4.52 & 1.916 \\
\hline To expand my knowledge & 0.682 & & & 4.85 & 1.630 \\
\hline $\begin{array}{l}\text { To know new and different } \\
\text { cultures }\end{array}$ & 0.840 & & & 5.43 & 1.424 \\
\hline Sport & 0.870 & & & 4.55 & 1.655 \\
\hline $\begin{array}{l}\text { To sport and develop my golf } \\
\text { skills }\end{array}$ & 0.684 & & & 5.25 & 1.369 \\
\hline To play a competitive sport & & & & \\
\hline To attend to tournaments & & & & & \\
\hline
\end{tabular}

The questionnaire provides 25 items on perceptions addressing organisational, social, psychological and economic aspects of the destination, golf courses and golf game perceptions. After VARIMAX rotation, a four-factor structure evolves from perceptions construct, namely 'quality' (18.22\%), 'maintenance' (17.16\%), 'tourism' (16.80\%), and 'golf' (11.95\%) explaining $64.12 \%$ of all variance. These three factors are grouping according to a descending order sorted from the scores of the loadings. For golf tourist's perceptions the KMO measure is 0.860 and the Bartlett's test of 
sphericity is significant at $\mathrm{p}=0.000$. Further all factors show an internal consistency superior to 0.84 measure by Cronbach's alpha.

Table 3 shows that golf tourists carry specific mental images towards the type of golf destination, quality and maintenance. Bearing in mind the literature review, we might assume that cognitive destination image is defined by these four factors. 'Quality' refers to premier players with high level of golf knowledge. Gastronomy, cultural offer and hospitality are complements of golf tourism, similarly entertainment and nightlife are also important features of a golf destination, in particular in socialrelated golf tourists. The tourist's perceptions about 'maintenance' are related to tees (0.747), fairways (0.729), greens (0.676), course (0.719), slow play management (0.728), green fee (0.742) and buggies prices $(0.612)$. The cognitive destination image is a complex portrait of variables ranging from golf courses features to the surrounding offer tied to local culture and heritage.

Golf tourist's responses on expectations were integrated into four factors, namely 'quality (21.76\%), 'tourism' (19.52\%), 'golf' (13.99\%), and 'economic' (8.67\%). Cronbach's Alpha coefficient of reliability was computed for each factor; all coefficients are considered 'good' as they assume values higher than 0.80. In addition, the KMO is 0.834 and the Bartlett test of sphericity is significant $(p<0.000)$ suggesting that the extraction is good.

The factors identified for expectations are similar to the perceptions what suggests that cognitive image and the emotional image measured only by the expectations overlap to each other. Even though, in case of expectations 'quality' shows higher values for the mean combined with low standard deviations. Indeed, the levels of consistency are higher suggesting that the emotional dimension is more solid, being this a signal that golf is perceived and expected to be more a social and personal reward than a competitive game.

The factors identified for motivations, perceptions, and expectations provide evidence for the multidimensionality of those constructs. We proceed with the analysis of the correlations as an exploratory tool to analyse linkages among factors and constructs. In line with the literature, the analysis of correlations suggest that the destination image is both a multi-process and sequential (Gallarza, Saura, and García, 2002). The main finding is that all three concepts are interplayed which lead us to a non-rejection decision on six above mentioned hypothesis.

Two noticeable correlations, correlation of 'social motivations' and the perception golf course quality (0.512), and, golf course facilities (0.464). So, there is a social valorisation for golf as suggested by Correia, Pintassilgo, Martins and Mendes (2006). There also is a positive correlation between 'sport motivations' and perceived quality of Algarve golf courses (0.408) and golf course facilities (0.418). 
Table 3 Principal Components Analysis after VARIMAX rotation for perceptions

\begin{tabular}{|l|l|l|c|c|c|}
\hline \multicolumn{1}{|c|}{ Components } & $\begin{array}{c}\text { Eigen } \\
\text { value }\end{array}$ & $\begin{array}{c}\text { Percent } \\
\text { explained } \\
\text { variance }\end{array}$ & $\begin{array}{c}\text { Consistency } \\
\text { (Cronbach's } \\
\text { Alpha) }\end{array}$ & Mean & $\begin{array}{c}\text { Standard } \\
\text { deviation }\end{array}$ \\
\hline Quality & & $18.218 \%$ & 0.918 & & \\
\hline Quality & 0.771 & & & 5.31 & 1.515 \\
\hline Supply of Premier courses & 0.708 & & & 5.33 & 1.519 \\
\hline Difficulty of the golf course & 0.676 & & & 5.17 & 1.554 \\
\hline Hygiene and changing rooms & 0.622 & & & 5.33 & 1.554 \\
\hline Courses with high quality & 0.658 & & & 5.43 & 1.463 \\
\hline The existence of 'Handicap' & 0.654 & & & 4.92 & 1.769 \\
\hline Maintenance & & $17.157 \%$ & 0.916 & & \\
\hline Maintenance of the tees & 0.747 & & & 5.34 & 1.578 \\
\hline Price of the green fee & 0.742 & & & 5.44 & 1.441 \\
\hline Maintenance of the fairways & 0.729 & & & 5.53 & 1.348 \\
\hline Slow Play Management & 0.728 & & & 5.10 & 1.729 \\
\hline Maintenance of the course & 0.712 & & & 5.81 & 1.376 \\
\hline Maintenance of the greens & 0.676 & & & 6.16 & 0.958 \\
\hline Price of the buggies & 0.612 & & & 5.20 & 1.665 \\
\hline Tourism & & $16.796 \%$ & 0.885 & & \\
\hline Transport & 0.755 & & & 5.19 & 1.449 \\
\hline Cultural attractions & 0.746 & & & 4.61 & 1.559 \\
\hline Gastronomy & 0.716 & & & 5.24 & 1.432 \\
\hline $\begin{array}{l}\text { Facility of access } \\
\text { available information }\end{array}$ & 0.711 & & & 5.23 & 1.494 \\
\hline Environmental policies & 0.668 & & & 5.01 & 1.672 \\
\hline Security & 0.646 & & & 5.27 & 1.369 \\
\hline Hospitality & 0.627 & & & 5.32 & 1.317 \\
\hline Golf & & $11.946 \%$ & 0.843 & & \\
\hline Caddie Master & 0.705 & & & 4.41 & 1.764 \\
\hline Fee of the tournaments & 0.684 & & & 4.28 & 1.713 \\
\hline Price of the Pro-Shop & 0.681 & & & 4.68 & 1.678 \\
\hline Maintenance of the buggies & 0.650 & & & 1.709 \\
\hline Scale From 1(tow) $7(v e r y$ & & & & \\
\hline
\end{tabular}

Scale: From 1(low) to 7 (very high) 
Table 4 Principal Components Analysis after VARIMAX rotation for expectations

\begin{tabular}{|l|l|l|c|c|c|}
\hline \multicolumn{1}{|c|}{ Components } & $\begin{array}{c}\text { Eigen } \\
\text { value }\end{array}$ & $\begin{array}{c}\text { Percent } \\
\text { explained } \\
\text { variance }\end{array}$ & $\begin{array}{c}\text { Consistency } \\
\text { (Cronbach's } \\
\text { Alpha) }\end{array}$ & Mean & $\begin{array}{c}\text { Standard } \\
\text { deviation }\end{array}$ \\
\hline Quality & & $21.761 \%$ & 0.932 & & \\
\hline Maintenance of the course & 0.798 & & & 6.23 & 0.809 \\
\hline Maintenance of the Fairways & 0.771 & & & 6.11 & 0.837 \\
\hline Landscape & 0.762 & & & 6.09 & 0.882 \\
\hline Maintenance of the Greens & 0.751 & & & 6.19 & 0.921 \\
\hline Quality & 0.739 & & & 5.94 & 1.075 \\
\hline Putting Green Area & 0.706 & & & 5.89 & 1.113 \\
\hline Supply of Premier courses & 0.661 & & & 5.81 & 1.120 \\
\hline Pitch and Put Areas & 0.629 & & & 5.43 & 1.419 \\
\hline Security & 0.623 & & & 5.94 & 1.124 \\
\hline Tourism & & $19.517 \%$ & 0.913 & & \\
\hline Commerce/shops & 0.737 & & & 5.15 & 1.672 \\
\hline $\begin{array}{l}\text { Facility of access and } \\
\text { available information }\end{array}$ & 0.764 & & & 5.61 & 1.354 \\
\hline Night life and entertainment & 0.720 & & & 5.25 & 1.553 \\
\hline Cultural attractions & 0.716 & & & 5.26 & 1.538 \\
\hline Social environment & 0.688 & & & 5.40 & 1.517 \\
\hline Climate & 0.684 & & & 5.66 & 1.502 \\
\hline Golf & & $13.989 \%$ & 0.897 & & \\
\hline Maintenance of the buggies & 0.752 & & & 5.67 & 1.233 \\
\hline Caddie Master & 0.676 & & & 5.19 & 1.386 \\
\hline $\begin{array}{l}\text { Hygiene and clearness of the } \\
\text { changing rooms }\end{array}$ & 0.664 & & & 5.54 & 1.441 \\
\hline Tournaments & 0.631 & & & 5.04 & 1.559 \\
\hline $\begin{array}{l}\text { Accessibilities to the golf } \\
\text { course }\end{array}$ & 0.625 & & & 5.72 & 1.085 \\
\hline Car parking & 0.616 & & & 5.62 & 1.232 \\
\hline Economic & 0.826 & & & 5.58 & 1.277 \\
\hline Price of Green Fee & 0.783 & & & 5.31 & 1.470 \\
\hline Price of the buggies & 0.720 & & & 5.20 & 1.527 \\
\hline Price of the Pro-Shop & 0.687 & & & 5.65 & 1.097 \\
\hline Service of the restaurant/bar & & & & \\
\hline Scale: From & & & & & \\
\hline
\end{tabular}

Scale: From 1 (worst than expected) to 7 (much better than expected) 


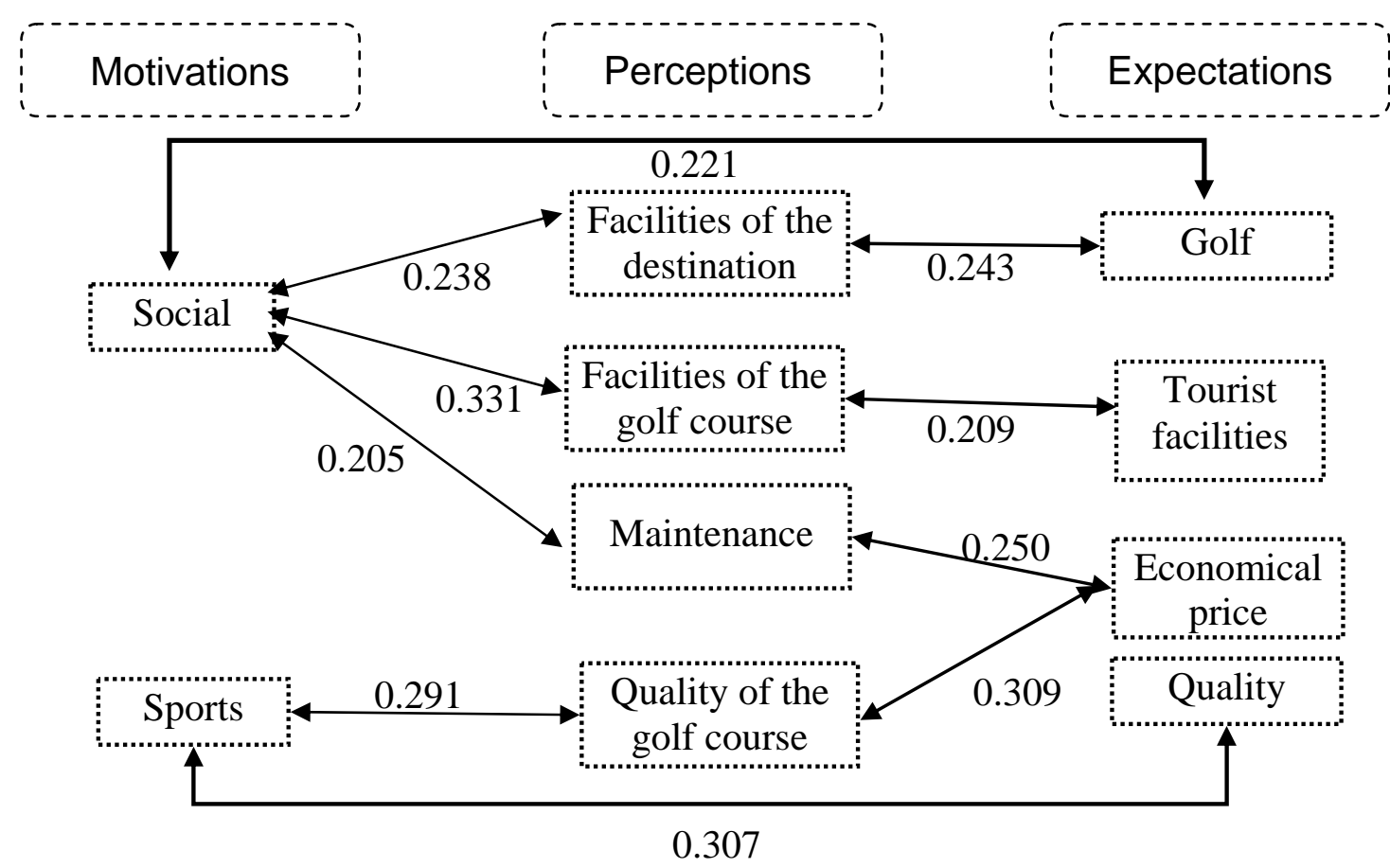

Pearson Correlations significant at 0.01 level

Figure 2 Correlation Analysis for the whole golf tourists

Concerning the golf course facilities, there is a positive correlation with value expectations (0.392), and 'social motivations' (0.464). Therefore, golf tourists recognise that golf in Vilamoura has a good purchase value. This is reiterated by the positive correlation of value expectations to course maintenance $(0.457)$ and the negative correlation with quality expectations (-0.401).

According to the exploratory analysis we might suggest that motivations, expectations, and perceptions are multidimensional constructs that are interplayed. From a more theoretical approach, both cognitive and emotional image have distinctive features despite the correlation. Portraying the image as multidimensional construct, it might be worthwhile to explore the market segmentation, as well as, the golf destination image patterns within segments.

Identifying market segments based on a three-dimensional perspective

This section deals with the market segmentation and the build-up process of the destination image among segments. In doing so, we proceed with market segmentation based on the identified factors, plotting market segments in perceptual maps for 
perceptions, expectations, and motivations. Similarly to previous section, we compute the correlations among factors and constructs for each market segment.

The non-hierarchical method of clustering (K-means) gather the surveyed population into three segments grounded by the factors previously identified by the PCA.

The probability of these groups being correctly classified was tested by the discriminant analysis that shows us that $98 \%$ of the members of each cluster are correctly classified (Table 5). We are confident suggesting that these three segments hold internal homogeneity and external heterogeneity. This was perceived by means of a CATPCA. Therefore, it is expectable that these groups show distinctive attributes. This is a complementary step that makes us proceeding with the analysis of the image among golf tourism segments. First a CATPCA was performed to perceive what factors distinguish best the clusters in their motivations, perceptions and expectations. Second a correlation analysis was performed as it was done in the first section of analysis.

The CATPCA scatter the three golf market segments in the perceptual map for the concepts of motivations, expectations, and perceptions.

Table 5 Confirmatory Analysis

\begin{tabular}{|c|c|c|c|c|c|c|}
\hline \multirow{2}{*}{\multicolumn{2}{|c|}{ 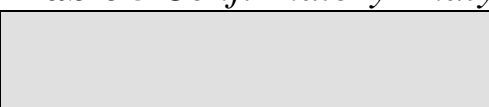 }} & \multirow{2}{*}{$\begin{array}{l}\text { Ward's } \\
\text { method }\end{array}$} & \multicolumn{4}{|c|}{ Predicted Group Membership } \\
\hline & & & 1 & 2 & 3 & Total \\
\hline \multirow{6}{*}{ Original } & \multirow{3}{*}{ Count } & 1 & 32 & 0 & 1 & 33 \\
\hline & & 2 & 0 & 24 & 0 & 24 \\
\hline & & 3 & 0 & 0 & 26 & 26 \\
\hline & \multirow{3}{*}{ Percent } & 1 & 97.0 & 0 & 3.0 & 100.0 \\
\hline & & 2 & 0.0 & 100.0 & 0.0 & 100.0 \\
\hline & & 3 & 0.0 & 0.0 & 100.0 & 100.0 \\
\hline \multirow{6}{*}{ Cross-validated $^{\mathrm{a}}$} & \multirow{3}{*}{ Count } & 1 & 31 & 1 & 1 & 33 \\
\hline & & 2 & 0 & 24 & 0 & 24 \\
\hline & & 3 & 0 & 0 & 26 & 26 \\
\hline & \multirow{3}{*}{ Percent } & 1 & 93.9 & 3.0 & 3.0 & 100.0 \\
\hline & & 2 & 0.0 & 100.0 & 0.0 & 100.0 \\
\hline & & 3 & 0.0 & 0.0 & 100.0 & 100.0 \\
\hline
\end{tabular}

a. Cross validation is done only for those cases in the analysis. In cross validation, each case is classified by the functions derived from cases than that case;

b. $98.8 \%$ of original grouped cases correctly classified;

c. $97.6 \%$ of cross-validated grouped cases correctly classified. 
Perceptual Map for Motivations

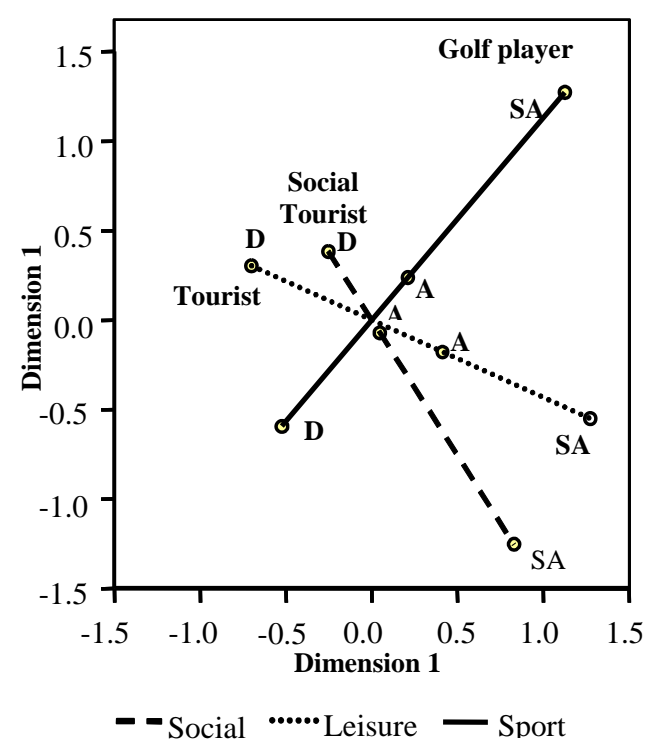

D - Disagree A - Agree SA - Strongly agree
Perceptual Map for Perceptions

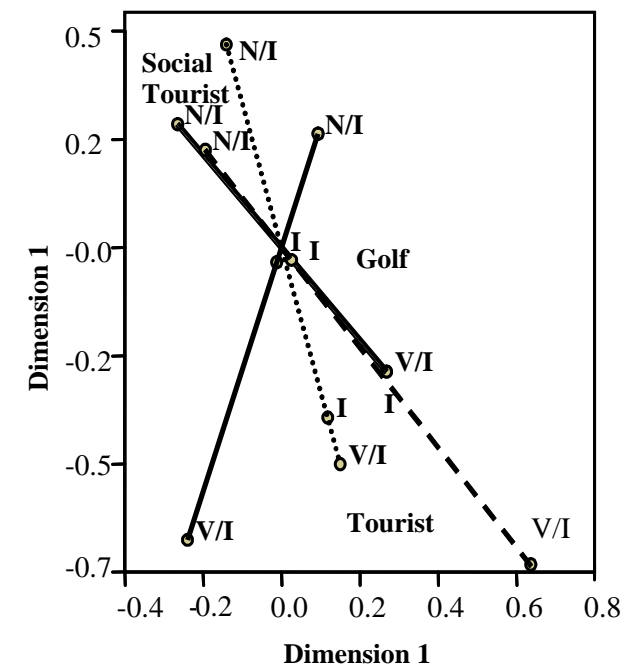

- Quality of golf ...... Maintenance of golf Destination - - Golf courses facilities

N/I - Not important I - Important V/I - Very important

Perceptual Map for Expectations

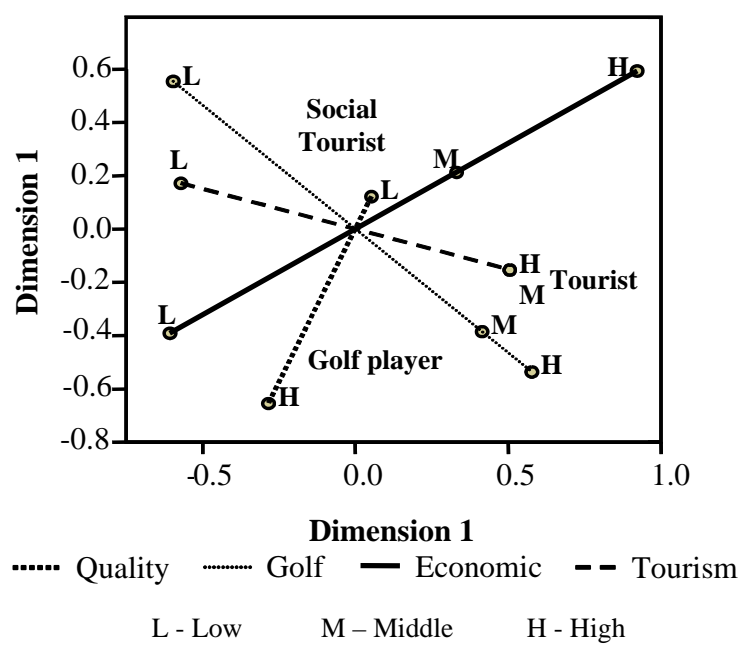

Figure 3 Joint plot of category points for motivations, perceptions and expectations and clusters 
Table 6 Socio-demographic and tripographic profile for clusters

\begin{tabular}{|c|c|c|c|}
\hline Variable & Tourist & Player & Social \\
\hline \multicolumn{4}{|l|}{ Gender } \\
\hline Female & $17.4 \%$ & $4.3 \%$ & $5.6 \%$ \\
\hline Male & $82.6 \%$ & $95.7 \%$ & $94.4 \%$ \\
\hline Age (Mean) & 43.38 & 42.22 & 45.74 \\
\hline \multicolumn{4}{|l|}{ Social Status } \\
\hline High & $30.4 \%$ & $44.4 \%$ & $39.4 \%$ \\
\hline Medium & $30.4 \%$ & $22.2 \%$ & $21.2 \%$ \\
\hline Low & $39.1 \%$ & $33.3 \%$ & $39.4 \%$ \\
\hline \multicolumn{4}{|l|}{ Nationality } \\
\hline Portugal & $13.0 \%$ & $0.0 \%$ & $2.8 \%$ \\
\hline United Kingdom & $65.2 \%$ & $65.2 \%$ & $66.7 \%$ \\
\hline Ireland & $8.7 \%$ & $21.7 \%$ & $8.3 \%$ \\
\hline Scotland & $13.0 \%$ & $4.3 \%$ & $5.6 \%$ \\
\hline Germany & $0.0 \%$ & $4.3 \%$ & $11.1 \%$ \\
\hline \multicolumn{4}{|l|}{ Day period to play } \\
\hline Morning & $66.7 \%$ & $85.7 \%$ & $84.4 \%$ \\
\hline Afternoon & $12.5 \%$ & $14.3 \%$ & $15.6 \%$ \\
\hline \multicolumn{4}{|l|}{ Location of accommodation } \\
\hline Outside the area of the golf courses & $19.0 \%$ & $34.8 \%$ & $25.7 \%$ \\
\hline Inside the area of the golf courses & $81.0 \%$ & $65.2 \%$ & $74.3 \%$ \\
\hline \multicolumn{4}{|l|}{ Type of accommodation } \\
\hline Hotel & $17.4 \%$ & $27.3 \%$ & $19.4 \%$ \\
\hline Aparthotel & $4.3 \%$ & $0.0 \%$ & $11.1 \%$ \\
\hline Own House & $26.1 \%$ & $13.6 \%$ & $5.6 \%$ \\
\hline Touristic Resort & $8.7 \%$ & $4.5 \%$ & $13.9 \%$ \\
\hline Apartment & $13.0 \%$ & $27.3 \%$ & $25.0 \%$ \\
\hline Villa & $30.0 \%$ & $27.3 \%$ & $25.0 \%$ \\
\hline
\end{tabular}

The three segments are plotted in distinctive areas of the perceptual map. According to their motivations, perceptions and expectations the clusters were labelled as 'Social tourist' (36 individuals), 'Golf Player' (23 individuals), 'Tourist' (24 individuals). 'Social tourist' appears in the middle of 'tourist' who is akin to social and leisure dimensions and 'golf player' tourist who priories the factor named 'sport'. Golf players are mainly motivated by the sport perceived as all the attributes and expecting to have high quality. 'Tourist' segment attaches more importance to the maintenance of golf course as well as the services either supplied in the destination or in the golf course as the most important. 'Tourist' does not report having higher perceptions on 
the four factors comprising the construct. Concerning the expectations, the perceptual map shows a more homogeneous distribution of the golf market segments. 'Golf player' segment holds high economic and touristic expectations for which the golf and the quality of the golf course are important. 'Social tourist' segment had reported high expectations towards both economic and the touristic factors. Finally 'tourist segment' is characterized by the moderated levels of expectation at all levels brought to analysis.

Table 6 shows the main socio-demographic and tripographic characteristics of these segments. These segments are mainly males with an average purchasing power, with more than forty years old. They prefer to play in the morning and be lodging in the area where they intend to play. Even tough most of the tourists are from United Kingdom. The 'tourist segment' comprises some Portuguese tourists (13\%). Ireland is mainly represented on 'social tourist segment'. The 'golf player segment' is the one with more German tourists. The 'tourist segment' tends to stay in own houses or private villas. The 'social tourist segment' divides their preferences within hotels, apartments or private villas, which is also the case of the 'golf player segment'.

A remarkable finding from the CATPCA analysis is the verifications of the hypothesis on internal correlations. Therefore, given the consistency of the market segments, we might expect that the multidimensionality of motivations, expectations, and perceptions is carried into the golf market segments. In another words, our hypothesis remain true either at a market level or segment level.

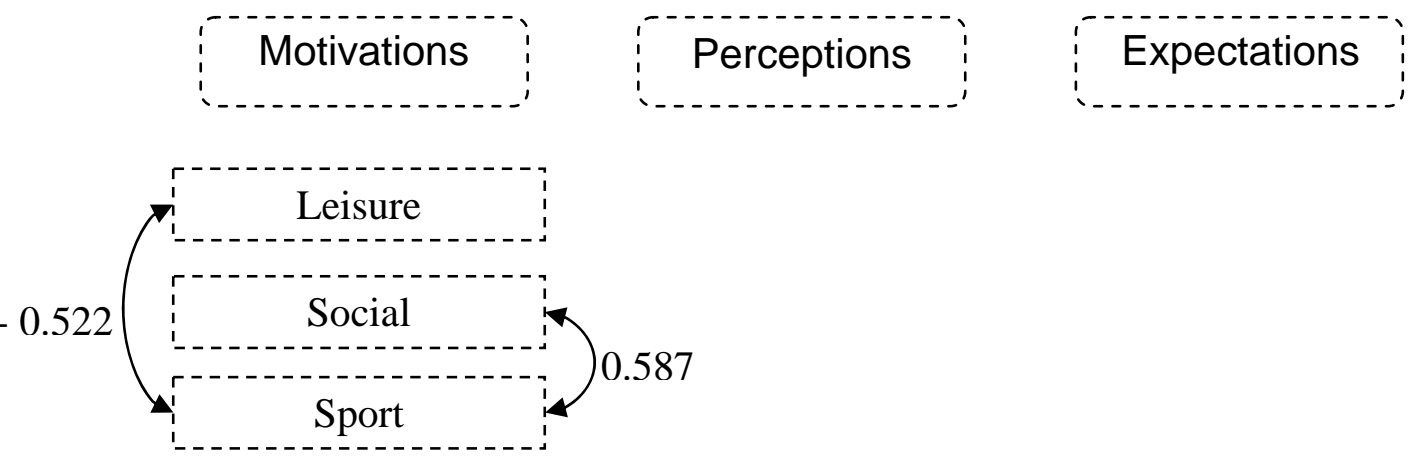

Pearson Correlations significant at 0.01 level

Figure 4 Correlations Analysis for the tourist segment

For 'tourists' only the motivations are inter-correlated, meaning that for this segment only H1 shall not be rejected (see Figure 4). 'Leisure' is negatively correlated to 'sport' motivations (-0.522). Conversely 'social' motivations appear correlated to 'sport' motivations (0.587). So, the 'sport' motivations are distinctive from 'leisure' ones which supports that existence of distinctive features of destination image for this 
market segment at an emotional level. At a cognitive level there are not internal correlations, this trend remains true for the expectations as the second measure of emotional component. For those tourists golf appears not as leisure activity instead is a social activity.

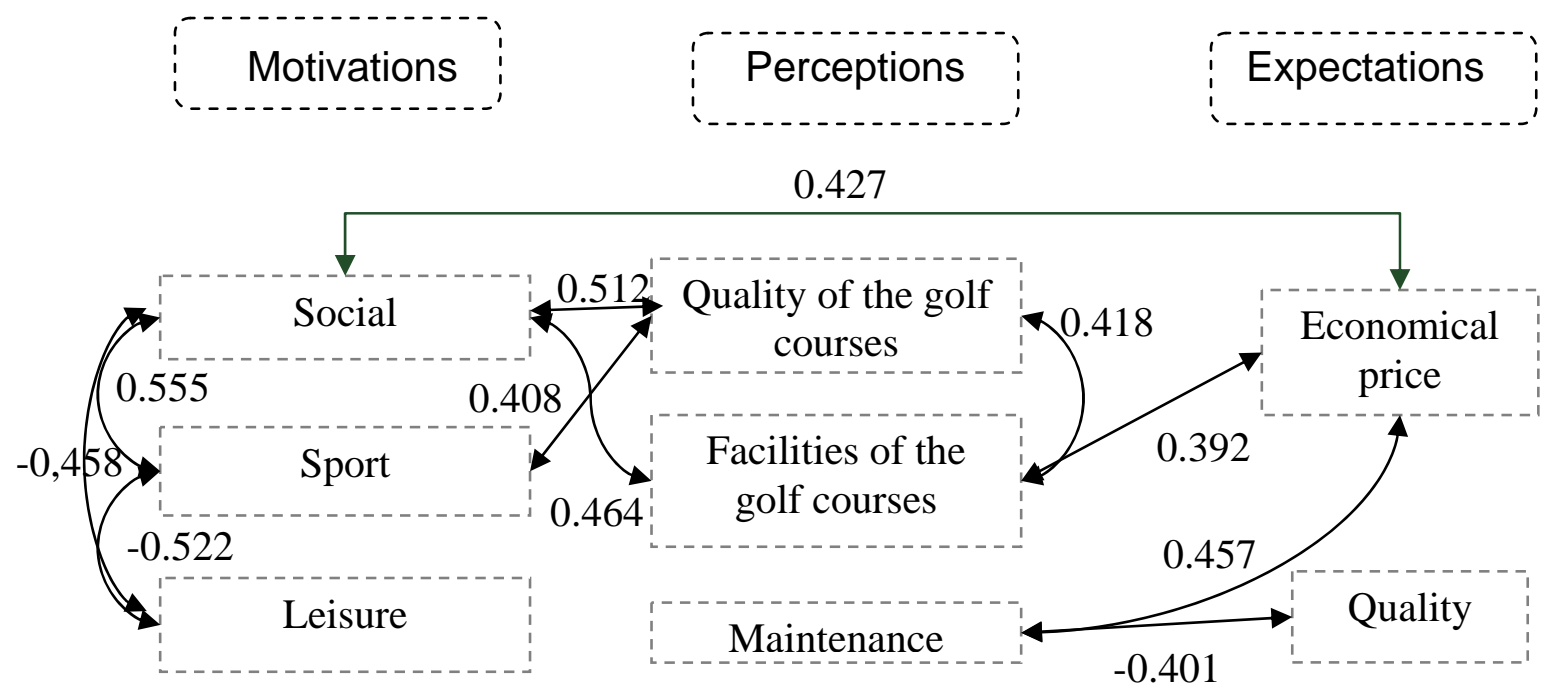

Pearson Correlations significant at 0.01 level

Figure 5 Correlations Analysis for the golf players

For the 'golf player' cluster the 'sport' motivations are positively correlated with 'social' motivations (0.555) and negatively correlated to 'leisure' (-0.522) (see Figure 5). The motivations of 'leisure' are also negatively correlated to 'social' motivations (-0.458). This suggests that cluster 2 attaches more importance to the golf as a sport and social happening rather than a leisure occupation. So, both 'tourists' and 'golf player' gives evidence for a negative correlation of 'leisure' and 'sport'. This supports the view according which 'leisure' and 'golf as a sport are distinguishable motivational factors. For this segment all the hypothesis has been proved.

Finally we look at the 'Social tourists' segment (Figure 6). 'Social motivations' are positively correlated with golf expectations (0.349) and golf course facilities (0.317). Inversely, these motivations are negatively correlated to 'leisure' motivations $(-0.391)$ what might imply that 'social tourist' perceives golf as social activity rather than a sport. 'Leisure' motivations are negatively correlated to perceptions on golf course facilities (0.371). Expectations held by this segment towards the value are positively correlated to perceptions golf course quality (0.462). 'Maintenance' is positively correlated to the general facilities in the destination (0.434). 


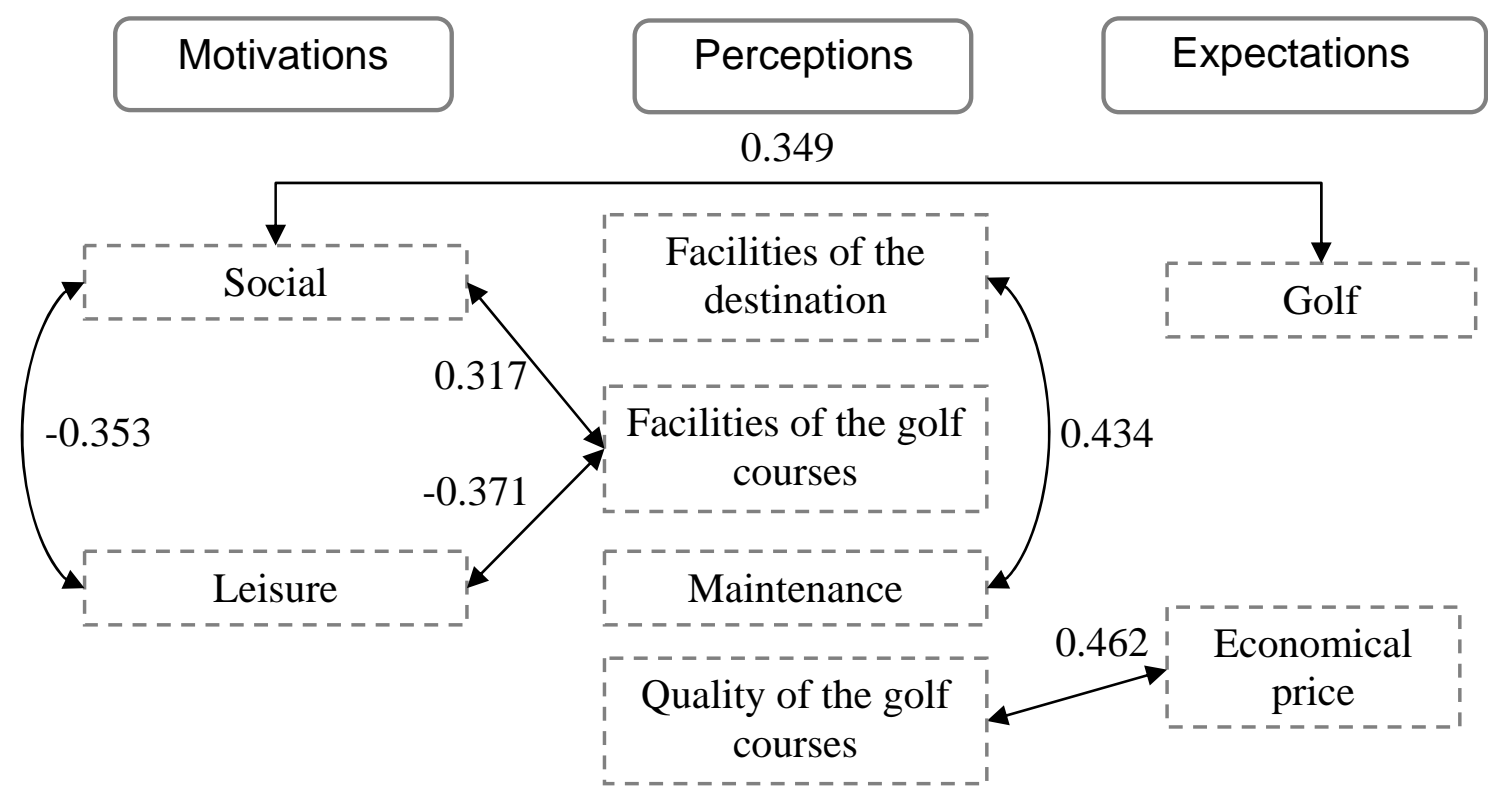

Pearson Correlations significant at 0.01 level

Figure 6 Correlations Analysis for the social tourists

Summing up the findings for the market segmentation, we observe a multidimensional model of golf destination image. Nevertheless this image is markedly heterogeneous among the three market segments. This main finding suggests that both cognitive and emotional components of destination image differ among segments; however both components should be put together.

\section{Conclusion, managerial implications and further research}

There are two noticeable conclusions. The first conclusion refers to the multidimensionality of motivations, perceptions, and expectations as measures of perceived destination image. Motivations are reported as having three factors, namely, 'social', 'sport' and 'leisure'. Both expectations and perceptions are grounded by four factors. At this level we fail to reject the hypothesis according to which the internal factors are inter-correlated suggesting the existence of linkages among them. For example, 'golf' and 'leisure' motivations appear to be negatively correlated.

The second arena of findings refers to the existence of market segments and the idiosyncratic perceived golf destination image (i.e. heterogeneous images within segments). The cluster analysis slips the golf market into three segments, namely: 'social tourist', 'golf player', and 'tourist'. For each market segment we identity 
different image patterns either at the internal level of each concepts or among concepts (e.g. motivation to perceptions) or even cognitive and emotional components (i.e. perceptions to expectations). So, destination image seems to be heterogeneous.

Destination image is a complex set of concepts that might differs according to the market segments. The added value by this research lies at the interplay of motivations, expectations, and motivations for the understanding of market segments. This piece of work puts forward an exploratory pathway to bring into play the perceived destination image as helpful construct for market segmentation.

From a practical perspective this research delivers insightful findings to the destination planning. Conceptualizing a golf destination implies a build-up process among the stakeholders. From a marketing perspective, this research contributes to the literature by alerting to the existence of different market segments. In other words, the market of golf tourism is broad and it does not unveil the internal attributes of the market. These markets segments are grounded by the expectations, motivations, and the perceptions. As constructs, theses three attributes should be understood as complex constructs with correlated dimensions. Therefore, it is suggested a fresher approach to the golf market segmentation guided by the psychological attributes rather than the classical attributes such as age, or schooling.

Regarding the destination planning and management the actor should take into consideration the importance of developing positive image which are linked to the levels of willingness to travel to a given golf destination. The existence of several groups of tourists calls for a more focused approach on the market. The multiplication of golf courses may not necessarily mean the appearance of a golf tourism destination. Indeed, a mature golf destination needs a wide range offer regarding the demand. Looking only into the motivations, we are aware about the existence of multiple motivations of the golf tourists. We deeply believe that an approach based on the motivations, expectations, and perceptions is an antibody against the massification of the golf tourism.

Some limitations are attached to this work. There is not an extensive literature in golf tourism. Therefore, the identifiable contributions come from the theoretical background developed by the scholars in other roads of research. This research also suffers from the lack of a 'thread' in terms of theoretical background. This opens avenues for further research. Also the using of different methodological tool-boxes might light up the saturation of some findings which will be an indicator of better understanding of the reality. Despite the well-established golf supply in the region, we cannot deny the local wide dimension of this research. Therefore, the research done in different geographical areas may reveal useful for the progress of the research. The limitations of this research should be the lever to push the research ahead. 


\section{References}

1. Ahmed, Z. (1991) The influence of the components of a state's tourist image on product positioning strategy. Tourism Management, 12(4), pp. 331-340.

2. Ashworth, G., and H. Voogd (1990) Selling the city: Marketing approaches in public sector urban planning. London: Belhaven Press.

3. Baloglu, S. (1997) The relationship between destination images and sociodemographic and trip characteristics of international travellers. Journal of Vacation Marketing, 3(3), pp. 221-233.

4. Baloglu, S. and K. McCleary (1999) A model of destination image formation. Annals of Tourism Research, 26(4), pp. 868-897.

5. Beerli, A. (1998) Imagen Exterior. In Gran Canaria Siglo XXI. Diagnostico de Situacion, Tomo II, Cabildo Insular de Universidad de Las Palmas de Gran Canaria, Gran Canaria.

6. Beerli, A. and J. Martín (2004) Tourists characteristics and the perceived image of tourist destinations: a quantitative analysis - a case study of Lanzarote, Spain. Tourism Management, 25(5), pp. 623-636.

7. Bem, D. (1967) Self-perception: An alternative interpretation of cognitive dissonance phenomena. Psychological Review, 74(3), pp. 183-200.

8. Bigné, J., M. Sánchez and J. Sánchez (2001) Tourism image, evaluation variables and after purchase behaviour: inter-relationship. Tourism Management 22(6), pp. 607-616.

9. Bitner, M. (1990) Evaluating service encounters: The effects of physical surroundings and employee responses. Journal of Marketing Research, 54(April), pp. 69-82.

10. Bojanic, D. (1996) Consumer perceptions of price, value and satisfaction in the hotel industry: an exploratory study. Journal of Hospitality and Leisure Marketing, 14(1), pp. 5-2.

11. Bramwell, B. and L. Rawding (1996) Tourism marketing images of industrial cities. Annals of Tourism Research, 23(1), pp. 201-221.

12. Buhalis, D. (2000) Marketing the competitive destination in the future. Tourism Management, 21(1), pp. 97-116.

13. Calantone, R., A., Benedetto, A. Hakan, and D. Bojanic (1989) Multiple multidimensional tourism positioning using correspondence analysis. Journal of Travel Research, 28(2), pp. 25-32.

14. Chang, T. and A. Wildt (1994) Price, product information, and purchase intention: An empirical study. Journal of the Academy of Marketing Science, 22(1), pp. 16-27.

15. Chianga, C. and S. Jang (2008) An expectancy theory model for hotel employee motivation. International Journal of Hospitality and Management, 27(2), pp. 313-322. 
16. Chon, K. (1989) Understanding recreational travellers' motivation, attitude and satisfaction. The Tourist Review, 44(1), pp. 3-7

17. Cohen, J. B. (1972) Behavioural science foundation of consumer behaviour. New York: Free Press.

18. Correia, A. C. Barros and L. Silvestre (2007) Golf tourism repeat choice behaviour in the Algarve: a mixed logic approach. Tourism Economics, 13(1), pp. 111127.

19. Correia, A. P. Valle and C. Moço (2007) Modelling motivations and perceptions of Portuguese tourists. Journal of Business Research, 60(1), pp. 76-80.

20. Correia, A., P. Pintassilgo, V. Martins and J. Mendes (2006) The Golf Players`Motivations - The Algarve Case. Tourism and Hospitality Research, Surrey Quarterly Review, 3(3), pp. 227-238.

21. Crask, M. and W. Perreault (1977) Validation of discriminant analysis in marketing research. Journal of Market Research, 14(February), pp. 60-68.

22. Crompton, J. (1979) Motivations of pleasure vacations. Annals of Tourism Research, 6(4), pp. 408-424.

23. Dann, G. (1977) Anomie, ego-enhancement and tourism. Annals of Tourism Research, 4(4), pp. 184-194.

24. Dann, G. (1981) Tourist motivation - An appraisal. Annals of Tourism Research, 8(2), pp. 187-219.

25. Dann, G. (1996) Tourists' images of a destination - An alternative analysis. Journal of Travel and Tourism Marketing, 5(1/2), pp. 41-55.

26. Ryan, R. and E. Deci (2000) Self-determination theory and the facilitation of intrinsic motivation, social development, and well-being. American Psychologist, 55(1), pp. 68-78.

27. Evans, M., A. Jamal and G. Foxall (2006) Consumer behaviour. West Sussex: John Wiley and Sons

28. Fakeye, P. and J. Crompton (1991) Image differences between prospectives, first-time, and repeat visitors to the lower Rio Grande valley. Journal of Travel Research, 32(2), pp. 10-16.

29. Fodness, D. (1994) Measuring tourist motivation. Annals of Tourism Research, 21(3), pp. 555-581.

30. Gallarza, G., G. Saura, H. Garcia (2002) Destination image: Towards a conceptual framework. Annals of Tourism Research, 29(1), pp. 56-78.

31. Gartner, W. (1989) Tourism image: attribute measurement of state tourism products using multidimensional techniques. Journal of Travel Research, 28(2), pp. 16-20.

32. Gartner, W. (1993) Image formation process. Journal of Travel and Tourism Marketing, 2(3), pp. 191-215. 
33. Gnoth, J. (1997) Tourism motivation and expectation formation. Annals of Tourism Research, 24(2), pp. 283-304.

34. Greenacre, M. (1983) Theory and applications of correspondence analysis. London: Academic Press.

35. Gunn, C. (1972) Vacationscape: Designing tourist regions. Washington DC: Taylor and Francis/University of Texas.

36. Guthrie J., and P. Gale (1991) Positioning Ski Areas. In New Horizons Conference Proceedings, University of Calgary, Calgary, pp. 551-569.

37. Hair, J., J. Anderson, R. Tatham and W. Black (1998) Multivariate data analysis. Upper Saddle River: Prentice Hall, $5^{\text {th }}$ ed.

38. Heiser, W. J. and J. Meulman (1994) Homogeneity analysis: exploring the distribution of variables and their nonlinear relationships. In: Krzanowski, W. (ed.) (1995) Recent advances in descriptive multivariate analysis. Oxford: Clarendon Press, pp. 51-89.

39. Holbrook, M. (1978) Beyond attitude structure: toward the informational determinants of attitude. Journal of Marketing Research 15(November), pp 545-556.

40. Holbrook, M. and R. Schindler (1996) Market segmentation based on age and attitude towards the Past: Concepts, methods and findings concerning nostalgic influences on customer taste. Journal of Business Research, 37(1), pp. 27-39.

41. Howard, J., and J. Sheth (1969) The theory of buyer behavior. New York: John Wiley and Sons.

42. Iso-Ahola, S. and R. Mannel (1987) Psychological nature of leisure and tourism experience. Annals of Tourism Research, 14(3), pp. 314-331.

43. Jayanti, R. and A. Gosh (1996) Service value determination: An integrative perspective. Journal of Hospitality and Leisure Marketing, 34(4), 5-25.

44. Kim and Yoon (2003) The hierarchical effects of effective and cognitive components on the tourism destination image. Journal of Travel and Tourism Marketing, 14(20), pp. 1-22.

45. Kotler (1982) Principles of marketing. New Jersey: Prentice Hall, $2^{\text {nd }}$ ed.

46. Kotler, P., D. Haider and I. Rein (1993) Marketing places. New York: Free Press.

47. Krippendorf, J. (1987) The holiday makers: Understanding the impact of leisure and travel. London: Heinemann.

48. Lancaster, K. J. (1966) A new approach to consumer theory. Journal of Political Economy, 74(2), pp. 132-157.

49. Lee, G., A. Morrison and J. O'Leary (2006) The economic value portfolio matrix: A target market selection tool for destination marketing organization. Tourism Management, 27(4), pp. 576-588. 
50. Leeuw, J. and W. Heiser (1980) Multidimensional scaling with restrictions on the configuration. In Krishnaiah, P. (ed.) Multivariate analysis, Vol. V. Amsterdam: North-Holland, pp. 501-522.

51. Lew, A. (1987) A framework of tourist attractions research. Annals of Tourism Research, 14(3), pp. 553-575.

52. MacKay, K. and D. Fesenmaier (1997) Pictorial element of destination in image formation. Annals of Tourism Research, 24(3), pp. 537-565.

53. McCabe, A. (2000) Tourism motivation process. Annals of Tourism Research, 2(4), pp. 1049-1052.

54. Meethan, K. (2001) Tourism in global society: Place, culture, consumption. Basingstoke: Palgrave.

55. Mohsin A. and C. Ryan (2003) Backpackers in the northern territory of Australia. International Journal of Tourism Research, 5(2), pp. 113-121.

56. Moutinho, L. (1987) Consumer behavior in tourism, European Journal of Marketing, 21(10), pp. 1-44.

57. Moutinho, L., (1982) An investigation of tourist behaviour in Portugal - a comparative analysis of pre-decision buying and post-purchasing attitudes of British, American and West German Tourists. PhD dissertation, University of Sheffield.

58. Olivier, R. (1997) Satisfaction: A behavioural perspective on the consumer. New York: McGraw-Hill.

59. Otto, J. and J. Ritchie (1996) The service experience in tourism. Tourism Management, 17(3), pp. 165-174.

60. Papatheodorou, A., (2003) Travel behaviour research: The leading edge. Annals of Tourism Research, 30(1), pp. 270-271.

61. Pearce, P. (1982) Perceived changes in holiday destinations. Annals of Tourism Research, 9(2), pp. 145-164.

62. Petrick, J. (2002) An examination of golf vacationers’ novelty. Annals of Tourism Research, 29(2), pp. 384-400.

63. Pike, S. (2002) Destination image analysis - A review of 142 papers from 1973 to 2000. Tourism Management, 23(5), pp. 541-549.

64. Prebensen, N., and B. Abelesn (2003) I'm not a typical tourist: German tourists' self-perception, activities and motivations. Journal of Travel Research, 41(4), pp. 416-420.

65. Prideaux, B. (2000) The resort development spectrum - A new approach to modelling resort development. Tourism Management, 21(3), pp. 225-240.

66. Seabra, C., J. Abrantes, L. Lages, (2007) The impact of using non-media information sources on the future use of mass media information sources: The mediating role of expectations fulfilment. Tourism Management, 28(6), pp. 1541-1554.

67. Selby, M., and N. Morgan (1996) Reconstructing place image: A case study of its role in destination market research. Tourism Management, 17(4), pp. 287-294. 
68. Selwyn, T. (1996) (ed.) The tourist image: Myths and myth making in tourism. Chichester: John Wiley and Sons.

69. Sherif, M. and C. Hovland (1961) Social judgment: assimilation and contrast effects in communication and attitude change. New Have, CT: Yale University Express.

70. Sheth, J., B. Newman and B. Gross (1991) Consumption values and market choices: theory and applications. Cincinnati, Ohio: South Western Publishing.

71. Silvestre, A. and A. Correia (2005) A second-order factor analysis model of measuring tourist's overall image of the Algarve (Portugal). Tourism Economics, 11(4), pp. 539-554.

72. Sirakaya, E., R. W. McLellan, M. Uysal (1996) Modelling vacation destination decisions: a behavioural approach. Recent Advances in Tourism Marketing Research, 5(1/2), pp 57-75.

73. Stabler, M. (1995) The image of destination regions: theoretical and empirical aspects. In Goodall, B. and G. Ashworth (eds.) Marketing in tourism industry: The promotion of destinations regions. London: Haworth Press PP 133-159.

74. Sternberg, E. (1997) The Iconography of the Tourism Experience. Annals of Tourism Research 24(4), pp. 951-969.

75. Tajfel, Henri and John C. Turner. (1986) The Social Identity Theory of Intergroup Behavior. In Worchel, S. and Austin W. (ed.) Psychology of Intergroup Relations. Chicago: IL: Nelson-Hall.

76. Tassiopoulos, D. and N. Haydam (2008) Golf tourists in South Africa: A demand-side study of a niche market in sports tourism. Tourism Management, 29(5), pp. 870-882.

77. Tolman, E. (1932) Purposive behaviour in animals and men. New York: Appleton.

78. Trauer, B., and C. Ryan (2006) Destination image, romance and place experience - An application of intimacy theory in tourism. Tourism Management, 26(4), pp. 481-491.

79. Um, S., and J. Crompton (1990) Attitude determinants in tourism destination choice. Annals of Tourism Research, 17(3), pp. 432-448.

80. Vogt, C. and K. Andereck, (2003) Destination perceptions across a vacation. Journal of Travel Research, 41(4), pp. 348-354.

81. Vroom, V. (1964) Work and motivation. New York: Wiley.

82. Walmsley, D. and J. Jenkins (1992) Tourism cognitive mapping of unfamiliar environments. Annals of Tourism Research, 19(2), pp. 268-286.

83. Ward, J. (1963) Hierarchical grouping to optimize an objective function. Journal of American Statistical Association, 58(301), pp. 236-244. 
84. Witt, C. and P. Wright (1992) Tourist motivation: Life after Maslow. In P. Johnson and B. Thomas (eds.) Choice and Demand in Tourism London: Mansell, pp. 33-55.

85. Woodside, A. and L. Jacobs (1985) Step Two in benefit segmentation: Learning the benefits realized by major travel markets. Journal of Travel Research, 24(1), pp. 7-14.

86. Woodside, A. and S. Lysonski (1989) A general model of travel destination choice. Journal of Travel Research, 27(4), pp. 8-14.

87. Worcester, R. (1997) Managing the image of bank: The glue that binds. International Journal of Bank Marketing, 15(5), pp. 146-152.

88. Yoon, Y., and M. Uysal (2005) An examination of the effects of motivation and satisfaction on destination loyalty: A structural model. Tourism Management, 26(1), pp. 45-56.

89. Zeithaml, V. (1988) Consumer perceptions of price, quality and value: A means-end model and synthesis of evidence. Journal of Marketing, 52(3), pp. 2-22.

RECEIVED: 14.11 .2008

ACCEPTED: 20.04.2009 